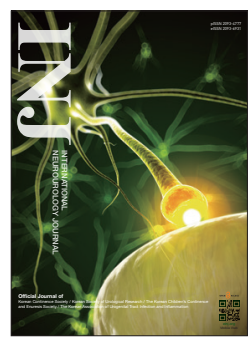

\title{
Second-Line Surgical Management After Midurethral Sling Failure
}

\author{
Joonbeom Kwon', Yeonjoo Kim¹, Duk Yoon Kim² \\ 'Department of Urology, Daegu Fatima Hospital, Daegu, Korea \\ ${ }^{2}$ Department of Urology, Catholic University of Daegu School of Medicine, Daegu, Korea
}

\begin{abstract}
Currently, the midurethral sling (MUS) is widely used as a standard treatment in patients with stress urinary incontinence (SUI). Several studies have reported the failure rate of MUS to be approximately $5 \%-20 \%$. In general, sling failure can be defined as persistent SUI after surgery or a temporary improvement in incontinence followed by recurrence. Failure is also often considered to include cases requiring secondary surgery due to mesh exposure, postoperative voiding difficulty, de novo urgency/urge incontinence, and severe postoperative pain. Because of the lack of large-scale, high-quality research on this topic, no clear guidelines exist for second-line management. To date, transurethral bulking agent injections, tape shortening, repeat MUS, pubovaginal sling (PVS) using autologous fascia, and Burch colposuspension are available options for second-line surgery. Repeat MUS is the most widely used second-line surgical method at present. Bulking agent injections have lower durability and efficacy than other treatments. Tape shortening demonstrates a relatively low success rate, but comparable outcomes if the period from first treatment to relapse is short. In patients with intrinsic sphincter deficiency, PVS and retropubic (RP) MUS can be considered first as second-line management because of their higher success rate than other treatments. When revision or reoperation is required due to prior mesh-related complications, PVS or colposuspension, which is performed without a synthetic mesh, is appropriate for second-line surgery. For patients with detrusor underactivity, a readjustable sling can be a better option because of the high risk of postoperative voiding dysfunction in PVS or RP slings.
\end{abstract}

Keywords: Urinary incontinence; Suburethral sling; Recurrence

- Conflict of Interest: No potential conflict of interest relevant to this article was reported.

\section{INTRODUCTION}

It has been reported that $13.6 \%$ of women suffer from stress urinary incontinence (SUI) in their lifetime [1]. The surgical standard for treating SUI has changed from the pubovaginal sling (PVS) and Burch colposuspension to the midurethral sling (MUS) because of comparable cure rates and lower surgical morbidity after the introduction of the MUS in 1996 [2-4]. The short-term cure rates for MUS have been reported to be high (70\%-98\%) [5]. However, its cure rate declines over time. The long-term objective and subjective cure rates for retropubic (RP) and transobturator (TO) slings were found to be $61.6 \%$ and $76.5 \%$, and $64.4 \%$ and $81.3 \%$, respectively [6]. Failure was reported in 5\%-20\% of patients [7]. Repeat MUS, PVS, Burch colposuspension, tape shortening, and transurethral bulking agent injections can be considered as second-line surgical procedures. However, there is not yet a consensus on which salvage intervention should be selected.

Corresponding author: Joonbeom Kwon (ib https://orcid.org/0000-0003-3781-5855 Department of Urology, Daegu Fatima Hospital, 99 Ayang-ro, Dong-gu, Daegu 41199, Korea

E-mail: aziru98@gmail.com

Submitted: August 3, 2020 / Accepted after revision: August 24, 2020 
Different definitions and categories of surgical failure after MUS have been used in the literature. Sling failure can clearly be defined as persistent or recurrent SUI. Meanwhile, mesh complications, voiding difficulty, and bothersome lower urinary tract symptoms, which reduce patient satisfaction, can be defined as sling failure in a broad sense. It seems reasonable to consider salvage treatment options after clearly addressing the reason for the failure of the previous procedure. Therefore, this review intends to help clinicians choose a more appropriate salvage procedure in various situations.

\section{DEFINITION OF FAILURE}

The reason for the various failure rates is that the definition of failure is not uniform. What is a failed sling? Postoperative SUI can be an example of failure. Some researchers have defined a relapse of urine leakage within 12 months as sling failure, which they distinguished from recurrent SUI, which was used to refer to the reoccurrence of urine leakage at over 12 months from the first sling [8]. Some authors have defined both persistent SUI and recurrent SUI as sling failure, regarding persistent SUI as the symptom occurring within 6 weeks after the first sling, and recurrent SUI as the symptom occurring after 6 weeks [9]. Others have defined retreatment at any time after previous MUS as a sling failure [10]. Situations that need secondary surgery, such as deterioration of lower urinary tract symptoms, severe postoperative pain, and mesh-related complications, can also be included as sling failure [11].

Failure should be assessed using a detailed history, physical examinations, and subjective or objective criteria, including voiding diaries, validated tools about patient satisfaction, stress test, a 24-hour pad test, cystoscopy, and urodynamic study.

\section{RISK FACTORS OF FAILURE}

In a single-center retrospective study of 1,225 MUS patients (955 RP slings and 270 TO slings), the multivariate analysis noted that body mass index $>25 \mathrm{~kg} / \mathrm{m}^{2}$ (odds ratio [OR], 2.9), mixed urinary incontinence $(\mathrm{OR}, 2.4)$, prior surgery for continence (OR, 2.2), intrinsic sphincter deficiency (ISD) (OR, 1.9), and diabetes $(\mathrm{OR}, 1.8)$ were significant independent predictors of sling failure [12]. A prospective study of 597 patients who underwent MUS (280 in the RP arm, 285 in the TO arm) revealed that previous incontinence surgery (OR, 1.99), maximum Q-tip excursion $<30^{\circ}(\mathrm{OR}, 1.89)$, Medical Epidemiologic and Social Aspect of Aging questionnaire urge score $>10$ (OR, 1.97), and pad weight (OR, 1.06 per $10 \mathrm{~g}$ ) were predictors of overall failure [13]. Preoperative urge incontinence may be a risk of sling failure. In patients with mixed urinary incontinence, the postoperative cure rate was lower in long-term follow-up after MUS than in pure SUI patients (85\% vs. 30\%) [14]. Not all postoperative voiding difficulties require surgical intervention, and most cases resolve by temporal catheterization. The incidence of postoperative voiding difficulty decreased from $20 \%$ on day 1 to $2 \%$ by 6 weeks [15]. In a populationbased cohort of 188,454 women who underwent a sling, revision or removal of the sling was required in a cumulative $3.7 \%$ of participants in 9 years of follow-up (1.3\% for urinary retention vs. $2.5 \%$ for mesh erosion) [16]. In the Trial of Midurethral Sling study, the RP approach demonstrated a higher incidence of postoperative voiding dysfunction. A surgical intervention was necessary for voiding difficulty in 3\% of patients who received RP slings and in $0 \%$ of those who received TO slings within 24 months of follow-up [17]. Concomitant prolapse surgery, age, preoperative peak urinary flow rate, and the Charlson comorbidity index score were reported as potential predictors of postoperative voiding difficulties [18-20]. Younger age, concurrent prolapse surgery, diabetes, previous bariatric surgery, and an RP sling were regarded as risk factors for vaginal mesh exposure $[16,21,22]$.

\section{SECOND-LINE SURGICAL MANAGEMENT}

\section{Transurethral Bulking Agent Injections}

Because it is less invasive, suitable for the office setting, and available under local anesthesia, bulking agent injections have been considered a viable option for failed MUS. A retrospective study of 73 patients who received Macroplastique and collagen injections reported complete resolution in 18 (24.7\%) and symptom improvement in $52(71.2 \%)$ at the first postinjection follow-up visit (4.2 months after injection) [23]. In another retrospective study comparing urethral bulking agent injections $(n=67)$ to repeat MUS $(n=98)$ in 165 patients who underwent a secondary procedure for failed MUS, failure was reported in 26 patients $(38.8 \%)$ after bulking agent injections and 11 patients (11.2\%) after repeat MUS [24]. Despite the low cure rate, subjective satisfaction or improvement has been reported to be relatively high in short-term results [25]. However, the objective cure rate was much lower than that found for repeat MUS [24]; moreover, few long-term results have been reported. Some 
studies have stated that repeat injections are necessary due to the decrease in efficacy with time [23,26-28]. Therefore, bulking agent injections are not adequate considering the long-term cure rate, except for some selected cases.

\section{Shortening of the Previously Implanted MUS}

Shortening of pre-existing mesh is a less invasive management strategy than other surgical options. However, only a few small studies have been reported. Lo et al. [29] reported an objective cure rate in $71.4 \%$ of 14 failed tension-free vaginal tape (TVT) patients. The mean period from initial to secondary surgery was 4 months, and the mean follow-up period was 19 months (range, 12-39 months). A study outcome of tape shortening for failed TO slings revealed cure rates of $70 \%$ and $60 \%$ at 1 and 3 years of follow-up. The mean period to tape shortening was 4.2 months (range, 1-12 months) [30]. Another study of 7 patients with mesh tightening and a mean follow-up period of 25 months reported cure in 3 patients (42.9\%) cure and improvement in $6(85.7 \%)$. The median interval from TO sling to tape shortening was 6 months [31]. Patterson et al. [32] reported different surgical outcomes of tape shortening depending on whether the first sling was performed using the RP route (a subjective cure rate of $88 \%$ ) or the TO route (a subjective cure rate of 45\%). Han et al. [33] compared 30 patients who underwent tape shortening to 36 who underwent repeat MUS. The mean delay to shortening of the tape was $90.2 \pm 77.5$ months. The overall cure rate was $46.7 \%$ in the patients who underwent tape shortening and $72.2 \%$ in those who underwent repeat MUS at 12 months of follow-up ( $\mathrm{P}=0.034)$. Comparing the study of Han et al. with other studies, some differences can be seen between the reported cure rates. The cure rate may depend on the interval from the first MUS to the secondary intervention, although there has been no comparative study to confirm this possibility.

\section{Repeat MUS}

As the MUS using synthetic tape became widespread as the primary management of SUI, the incidence of MUS failure also increased. Due to the lack of a clear guideline regarding salvage options after sling failure, many clinicians have tried MUS as a secondary procedure and so far have shown relatively good results $[34,35]$. The success rate of repeat MUS reported so far varies widely (40\%-90\%) among researchers. The reason for this is that the criteria used to define cure or success in each study were different, the follow-up periods were different, and the results were also different depending on whether $\mathrm{RP}$ or $\mathrm{TO}$ slings were used $[9,33,36-40]$.

A retrospective study with 77 patients who underwent TVT $(n=48)$ or TO tape $(n=29)$ as secondary management revealed overall success rates of $71 \%$ and $48 \%$, respectively $(\mathrm{P}=0.04)$, meaning that repeat RP slings were more successful than repeat TO slings. The preoperative incidence of ISD was higher in the patients who underwent repeat MUS after sling failure than in those who did not require secondary management (31\% vs. $13 \%, \mathrm{P}<0.001)$. The subjective cure rate was higher in the primary management group (86\%) than in the secondary management group (62\%) [36]. Conversely, a cohort study of 112 recurrent SUI patients who underwent repeat MUS revealed an overall subjective success rate of $76.8 \%$ at 21 months of followup. There was no significant difference in outcomes between $\mathrm{RP}$ and TO slings [40]. A retrospective study reviewing $80 \mathrm{pa}-$ tients who underwent repeat MUS showed that repeat MUS had a lower success rate than primary MUS ( $55 \%$ vs. $81 \%, \mathrm{P}<$ 0.0001). A history of prior anti-incontinence procedures, a positive supine stress test, and a TO sling were independent risk factors for sling failure [39]. Complications such as voiding dysfunction, de novo urgency, urethra, bladder, and vaginal perforation happened more in RP slings, while chronic groin pain occurred more in TO slings [41].

\section{Readjustable Slings and Spiral Slings}

In a prospective study of 130 recurrent SUI patients, insertion of an adjustable continence therapy (ACT) device, which consists of 2 adjustable balloons aimed to be located just distal to the urethrovesical junction bilaterally, demonstrated a cure rate of 52\% (67 of 130) and an $80 \%$ improvement rate at a 1-year follow-up [42]. Another study of 57 patients who had recurrent SUI and received ACT implantation as secondary management reported a $68 \%$ success rate after 6 years [43]. Schmid et al. [44] reported an $84 \%$ ( 21 of 25 ) cure rate in patients who experienced failure of MUS as prior incontinence surgery and were treated with an AMI adjustable sling system as a secondary treatment at 1 year of follow-up. A retrospective study of the Remeex readjustable sling, which was conducted among 205 patients after primary failure of MUS, revealed a cure rate of $71.7 \%$ during a mean follow-up of 89 months (range, 26-159 months). Eighty-eight patients (42.9\%) required re-adjustment (82 cases of tension increase and 6 cases of tension reduction) [45]. Compared with the standard sling, a readjustable sling seems to result in increased success rates and decreased compli- 
cations as a salvage procedure because of the ability to readjust inadequate tension, which could induce recurrence of incontinence or postoperative bladder outlet obstruction. However, no comparative studies with other types of MUS have yet been conducted.

The success rates after spiral sling placement were reported to be $70 \%-75 \%$ at $15-26$ months of follow-up. Due to the nature of the procedure, there were several complications such as intraoperative bladder neck perforation produced by dorsal urethrolysis, or cases that required urethral reconstruction during a salvage procedure after secondary failure $[46,47]$.

\section{PVS With Autologous Rectus Fascia}

The cure rates of PVS using autologous fascia as second-line management have been reported to be $60 \%-80 \%$ [48-52]. A retrospective study of 66 patients (16 pure SUI vs. 50 mixed incontinence) who received an autologous PVS after failed MUS reported an SUI cure rate of $69.7 \%$. Patients with pure SUI showed a higher cure rate $(62.6 \%)$ than those with mixed incontinence (30.0\%) [49]. In another study of 35 patients who underwent autologous fascial sling after failed MUS, an assessment was possible in 21 patients. Preoperatively, 13 patients had a failed RP sling, and 8 had a failed TO sling. There were 13 patients with preoperative mixed urinary incontinence and 12 with urethral hypermobility. Eight patients had concomitant sling excision due to obstruction or pain. Success occurred in 16 patients (76.2\%) according to the Patient Global Impression of Improvement questionnaire for a median follow-up of 74 months. Concurrent sling excision, mixed urinary incontinence, age, length of follow-up, and first surgery type (RP vs. TO) had no statistical impact on outcomes [50]. In studies comparing PVS with RP slings, some reported similar success rates and complications between the 2 groups [51], while others noted that PVS had a higher surgical success rate and more complications related to postoperative voiding difficulty [52, 53].

\section{Burch Colposuspension}

Burch colposuspension as a secondary treatment after failed MUS has shown objective and subjective cure rates of 54\%$77 \%$ and $85 \%-93 \%$, respectively [54-57]. No studies have yet compared Burch colposuspension with other incontinence surgery as salvage procedures. The SISTEr (Stress Incontinence Surgical Treatment Efficacy) trial, a multicenter randomized comparative study, was conducted in a total of 655 SUI patients who had not previously received anti-incontinence surgery, and compared 329 patients who received colposuspension with 326 patients who received PVS. In total, 520 patients completed the outcome assessment. The success rate specific to SUI was higher for PVS than for Burch colposuspension (66\% vs. 49\%, P< 0.001), and adverse events such as urinary tract infections, voiding difficulty, postoperative de novo urgency, and urge incontinence also were higher in patients who received PVS [58]. Compared with MUS, colposuspension exhibited no difference in subjective and objective cure rates even at a long-term followup [59]. Amaye-obu and Drutz [60], in a study of 26 patients, showed that the cure rate of colposuspension declined to $81 \%$, $25 \%$, and $0 \%$ as the numbers of previous anti-incontinence operations increased to 1,2, and 3, respectively. According to this result, it would be better to avoid colposuspension if the patient has received anti-incontinence surgery twice or more. A randomized controlled trial comparing TVT to laparoscopic colposuspension in recurrent SUI patients exhibited similar cure rates and complications in the short-term follow-up [61]. If the recent issue of the increasing risk of mesh-related complications is considered, colposuspension might be a better alternative option as second-line management for failed MUS.

\section{Considerations at the Time of Planning Second-Line Surgery Concurrent excision or removal of the prior sling}

There is no consensus on whether the prior implanted sling should be removed $[62,63]$. Some agree with removing the prior sling so that the new sling is not prohibited from being placed in a proper position along with the midurethra. On the other hand, the objection has been raised that doing so may increase unnecessary morbidities such as a longer operation time, more bleeding, and possible urethral injury, which would not occur if concurrent excision is not performed. Steele et al. [63] compared subjective improvement in 61 patients who performed repeat MUS, of whom 28\% (17 of 61) and 72\% (44 of 61) underwent concurrent removal of prior sling or did not, respectively. Using the Urogenital Distress Index, Incontinence Severity Index, and Incontinence Impact Questionnaire, there was no difference in subjective voiding symptoms and operative complications between the 2 groups. In a retrospective study of 66 patients who underwent PVS as a second-line treatment, mesh removal was performed in 27 patients (21 before PVS, 6 concurrent excisions). Mesh excision was not associated with worse outcomes $(\mathrm{P}=0.013)$ [49]. Another retrospective study 
of 21 patients who underwent PVS after failed MUS resulted in no statistical impact according to whether concomitant sling excision was performed $(n=8)$ or not $(n=13)(P=0.62)$ [50]. However, it seems reasonable to remove the first sling if repeat surgery is necessary due to the complications related to mesh exposure, pain, and postoperative voiding difficulty. Jambusaria et al. [64] noted that pain was improved in more than $60 \%$ of patients by complete or partial excision of mesh in patients who suffered pain after primary MUS for a mean 29 weeks of follow-up.

\section{ISD versus urethral hypermobility}

ISD is one of the critical causes of primary sling failure. When second-line management is required, an RP sling or PVS can be considered first because of their higher success rates in SUI patients with ISD. A TO sling supports the lower surface of the midurethra horizontally in the resting position, while an RP sling or PVS supports a larger surface of the midurethra circumferentially with a U-shape. Therefore, it seems that urethral resistance is reinforced more by RP slings and PVS. Several clinical studies have reported higher success rates of RP slings and PVS compared to TO slings as secondary management in failed MUS [36,39,51]. If ISD is accompanied after sling failure, an RP sling, PVS, or adjustable sling can be considered first. Contrary, if urethral hypermobility is dominant, colposuspension could be a better alternative option [65].

\section{Mesh complications}

In the last decade, the use of commercial mesh for pelvic organ prolapse repair has been suspended in several countries due to the occurrence of some severe mesh-related complications. Some countries have prohibited the use of synthetic mesh even for SUI treatment. The overall rates of mesh erosion or extrusion have been reported to be $2.4 \%$ with TO slings versus $2.1 \%$ with RP slings. Nevertheless, a Cochrane review with high-level evidence supports the long-term effectiveness and tolerable adverse events of MUS using type I polypropylene mesh [5]. The reasons for the recent increase in mesh-related complications are as follows: First, the incidence of complications has increased due to an increase in synthetic mesh utilization [66]. Second, the problem of the mesh material itself can be considered. Despite discordant opinions on this issue, there is no clear evidence of a causal relationship between polypropylene mesh and systemic inflammation or an abnormal host response, according to a recent review by the International Consultation on Incontinence [67]. Third, the widespread use of synthetic mesh in SUI patients can lead to an increased incidence of inadequate surgical performance by inexperienced surgeons [68,69]. Risk factors affecting mesh-related complications include factors related to wound healing such as diabetes, smoking, nutritional deficiency, and old age, as well as intraoperative factors such as bleeding, hematoma, and trocar perforation into the urinary tract. In a patient with a failed MUS accompanied by mesh-related complications, PVS or colposuspension rather than repeat MUS can be considered first as a salvage treatment [65].

\section{Postoperative lower urinary tract symptoms}

After repeat MUS, the rate of de novo urgency and urge incontinence was reported to be $6 \%-30 \%$, and that of urinary retention was reported to be $10 \%-14 \%$ depending on the study $[36,49,70]$. As mentioned earlier, the long-term cure rates of RP slings and PVS were reported to be higher than those of TO slings, whereas postoperative voiding difficulty was also reported to be higher for those modalities than for TO slings. Little is known about the comparative outcome of de novo urgency and urge incontinence between secondary RP and TO tape. However, the incidence of storage symptoms after MUS in primary SUI patients was not different between the RP and TO approaches [17,67].

A readjustable sling can be a better option for patients who have recurrent SUI with detrusor underactivity to avoid postoperative voiding difficulties [62]. When a revision is planned due to postoperative voiding difficulties, it should be noted that complete excision of the mesh can produce a higher incidence of SUI recurrence than occurs after partial excision or urethrolysis [64].

\section{CONCLUSIONS}

There is not yet any consensus regarding the choice of adequate second-line surgery for failed MUS. However, it is necessary to approach surgical options according to the cause of the previous failure rather than uniformly determining a single treatment option. Since transurethral bulking agent injections or tape shortening can be performed with minimal invasiveness, they may be suitable as office-based procedures, but have lower durability and efficacy than other treatment options. Repeat MUS is still being performed most frequently, and recently, PVS and colposuspension are receiving attention again because issues relating to the mesh-related complications have been highlighted. 


\section{AUTHOR CONTRIBUTION STATEMENT}

\author{
- Conceptualization: JK \\ - Data curation: JK, DYK \\ - Formal analysis: $J K, D Y K$ \\ - Methodology: JK \\ - Project administration: JK, DYK \\ - Writing-original draft: $J K$ \\ - Writing-review \& editing: $J K, D Y K$
}

\section{ORCID}

$\begin{array}{ll}\text { Joonbeom Kwon } & 0000-0003-3781-5855 \\ \text { Duk Yoon Kim } & 0000-0001-8341-3123\end{array}$

\section{REFERENCES}

1. Wu JM, Matthews CA, Conover MM, Pate V, Jonsson Funk M. Lifetime risk of stress urinary incontinence or pelvic organ prolapse surgery. Obstet Gynecol 2014;123:1201-6.

2. Choi JB, Han KD, Ha US, Hong SH. Efficacy and safety of incontinence surgery according to the surgeon's specialty and performance of a preoperative urodynamic study. Int Neurourol J 2018; 22:305-12.

3. Kim A, Kim S, Kim HG. Current overview of surgical options for female stress urinary incontinence. Int Neurourol J 2020;24:222-30.

4. Leach GE, Dmochowski RR, Appell RA, Blaivas JG, Hadley HR, Luber KM, et al. Female Stress Urinary Incontinence Clinical Guidelines Panel summary report on surgical management of female stress urinary incontinence. The American Urological Association. J Urol 1997;158(3 Pt 1):875-80.

5. Ford AA, Rogerson L, Cody JD, Aluko P, Ogah JA. Mid-urethral sling operations for stress urinary incontinence in women. Cochrane Database Syst Rev 2017;7:CD006375.

6. Leone Roberti Maggiore U, Finazzi Agrò E, Soligo M, Li Marzi V, Digesu A, Serati M. Long-term outcomes of TOT and TVT procedures for the treatment of female stress urinary incontinence: a systematic review and meta-analysis. Int Urogynecol J 2017;28: 1119-30.

7. Liapis A, Bakas P, Creatsas G. Long-term efficacy of tension-free vaginal tape in the management of stress urinary incontinence in women: efficacy at 5- and 7-year follow-up. Int Urogynecol J Pelvic Floor Dysfunct 2008;19:1509-12.

8. Smith AR, Artibani W, Drake MJ. Managing unsatisfactory outcome after mid-urethral tape insertion. Neurourol Urodyn 2011;
30:771-4.

9. Lee KS, Doo CK, Han DH, Jung BJ, Han JY, Choo MS. Outcomes following repeat mid urethral synthetic sling after failure of the initial sling procedure: rediscovery of the tension-free vaginal tape procedure. J Urol 2007;178(4 Pt 1):1370-4.

10. Richter HE, Diokno A, Kenton K, Norton P, Albo M, Kraus S, et al. Predictors of treatment failure 24 months after surgery for stress urinary incontinence. J Urol 2008;179:1024-30.

11. Kavanagh A, Sanaee M, Carlson KV, Bailly GG. Management of patients with stress urinary incontinence after failed midurethral sling. Can Urol Assoc J 2017;11(6Suppl2):S143-6.

12. Stav K, Dwyer PL, Rosamilia A, Schierlitz L, Lim YN, Lee J. Risk factors of treatment failure of midurethral sling procedures for women with urinary stress incontinence. Int Urogynecol J 2010;21: 149-55.

13. Richter HE, Litman HJ, Lukacz ES, Sirls LT, Rickey L, Norton P, et al. Demographic and clinical predictors of treatment failure one year after midurethral sling surgery. Obstet Gynecol 2011;117:91321.

14. Holmgren C, Nilsson S, Lanner L, Hellberg D. Long-term results with tension-free vaginal tape on mixed and stress urinary incontinence. Obstet Gynecol 2005;106:38-43.

15. Ferrante KL, Kim HY, Brubaker L, Wai CY, Norton PA, Kraus SR, et al. Repeat post-op voiding trials: an inconvenient correlate with success. Neurourol Urodyn 2014;33:1225-8.

16. Jonsson Funk M, Siddiqui NY, Pate V, Amundsen CL, Wu JM. Sling revision/removal for mesh erosion and urinary retention: long-term risk and predictors. Am J Obstet Gynecol 2013;208:73.

17. Richter HE, Albo ME, Zyczynski HM, Kenton K, Norton PA, Sirls LT, et al. Retropubic versus transobturator midurethral slings for stress incontinence. N Engl J Med 2010;362:2066-76.

18. Linder BJ, Trabuco EC, Gebhart JB, Klingele CJ, Occhino JA, Elliott DS, et al. Can urodynamic parameters predict sling revision for voiding dysfunction in women undergoing synthetic midurethral sling placement? Female Pelvic Med Reconstr Surg 2019;25:63-6.

19. Ripperda CM, Kowalski JT, Chaudhry ZQ, Mahal AS, Lanzer J, Noor N, et al. Predictors of early postoperative voiding dysfunction and other complications following a midurethral sling. Am J Obstet Gynecol 2016;215:656.

20. Salin A, Conquy S, Elie C, Touboul C, Parra J, Zerbib M, et al. Identification of risk factors for voiding dysfunction following TVT placement. Eur Urol 2007;51:782-7.

21. Chen HY, Ho M, Hung YC, Huang LC. Analysis of risk factors associated with vaginal erosion after synthetic sling procedures for stress urinary incontinence. Int Urogynecol J Pelvic Floor Dysfunc 
2008;19:117-21.

22. Linder BJ, El-Nashar SA, Carranza Leon DA, Trabuco EC. Predictors of vaginal mesh exposure after midurethral sling placement: a case-control study. Int Urogynecol J 2016;27:1321-6.

23. Dray EV, Hall M, Covalschi D, Cameron AP. Can urethral bulking agents salvage failed slings? Urology 2019;124:78-82.

24. Gaddi A, Guaderrama N, Bassiouni N, Bebchuk J, Whitcomb EL. Repeat midurethral sling compared with urethral bulking for recurrent stress urinary incontinence. Obstet Gynecol 2014;123: 1207-12.

25. Lee HN, Lee YS, Han JY, Jeong JY, Choo MS, Lee KS. Transurethral injection of bulking agent for treatment of failed mid-urethral sling procedures. Int Urogynecol J 2010;21:1479-83.

26. Chrouser KL, Fick F, Goel A, Itano NB, Sweat SD, Lightner DJ. Carbon coated zirconium beads in beta-glucan gel and bovine glutaraldehyde cross-linked collagen injections for intrinsic sphincter deficiency: continence and satisfaction after extended followup. J Urol 2004;171:1152-5.

27. Gorton E, Stanton S, Monga A, Wiskind AK, Lentz GM, Bland DR. Periurethral collagen injection: a long-term follow-up study. BJU Int 1999;84:966-71.

28. Lone F, Sultan AH, Thakar R. Long-term outcome of transurethral injection of hyaluronic acid/dextranomer (NASHA/Dx gel) for the treatment of stress urinary incontinence (SUI). Int Urogynecol J 2010;21:1359-64.

29. Lo TS, Wang AC, Liang CC, Long CY, Lee SJ. Treatment for unsuccessful tension-free vaginal tape operation by shortening pre-implanted tape. J Urol 2006;175:2196-9.

30. Kim S, Son JH, Kim HS, Ko JS, Kim JC. Tape shortening for recurrent stress urinary incontinence after transobturator tape sling: 3-year follow-up results. Int Neurourol J 2010;14:164-9.

31. de Landsheere L, Lucot JP, Foidart JM, Cosson M. Management of recurrent or persistent stress urinary incontinence after TVT-O by mesh readjustment. Int Urogynecol J 2010;21:1347-51.

32. Patterson D, Rajan S, Kohli N. Sling plication for recurrent stress urinary incontinence. Female Pelvic Med Reconstr Surg 2010;16: 307-9.

33. Han JY, Moon KH, Park CM, Choo MS. Management of recurrent stress urinary incontinence after failed midurethral sling: tape tightening or repeat sling? Int Urogynecol J 2012;23:1279-84.

34. Ashok K, Wang A. Recurrent urinary stress incontinence: an overview. J Obstet Gynaecol Res 2010;36:467-73.

35. Walsh CA. Recurrent stress urinary incontinence after synthetic mid-urethral sling procedures. Curr Opin Obstet Gynecol 2011;23: 355-61.
36. Stav K, Dwyer PL, Rosamilia A, Schierlitz L, Lim YN, Chao F, et al. Repeat synthetic mid urethral sling procedure for women with recurrent stress urinary incontinence. J Urol 2010;183:241-6.

37. Liapis A, Bakas P, Creatsas G. Tension-free vaginal tape in the management of recurrent urodynamic stress incontinence after previous failed midurethral tape. Eur Urol 2009;55:1450-5.

38. Tsivian A, Neuman M, Yulish E, Shtricker A, Levin S, Cytron S, et al. Redo midurethral synthetic sling for female stress urinary incontinence. Int Urogynecol J Pelvic Floor Dysfunct 2007;18:23-6.

39. Smith AL, Karp DR, Aguilar VC, Davila GW. Repeat versus primary slings in patients with intrinsic sphincter deficiency. Int Urogynecol J 2013;24:963-8.

40. Meyer F, Hermieu JF, Boyd A, Dominique S, Peyrat L, Haab F, et al. Repeat mid-urethral sling for recurrent female stress urinary incontinence. Int Urogynecol J 2013;24:817-22.

41. Lucas MG, Bosch RJ, Burkhard FC, Cruz F, Madden TB, Nambiar $\mathrm{AK}$, et al. EAU guidelines on surgical treatment of urinary incontinence. Eur Urol 2012;62:1118-29.

42. Aboseif SR, Franke EI, Nash SD, Slutsky JN, Baum NH, Tu le M, et al. The adjustable continence therapy system for recurrent female stress urinary incontinence: 1-year results of the North America Clinical Study Group. J Urol 2009;181:2187-91.

43. Kocjancic E, Crivellaro S, Ranzoni S, Bonvini D, Grosseti B, Frea B. Adjustable continence therapy for severe intrinsic sphincter deficiency and recurrent female stress urinary incontinence: long-term experience. J Urol 2010;184:1017-21.

44. Schmid C, Bloch E, Amann E, Mueller MD, Kuhn A. An adjustable sling in the management of recurrent urodynamic stress incontinence after previous failed midurethral tape. Neurourol Urodyn 2010;29:573-7.

45. Errando-Smet C, Ruiz CG, Bertrán PA, Mavrich HV. A re-adjustable sling for female recurrent stress incontinence and intrinsic sphincteric deficiency: long-term results in 205 patients using the Remeex sling system. Neurourol Urodyn 2018;37:1349-55.

46. Rodriguez AR, Hakky T, Hoffman M, Ordorica R, Lockhart J. Salvage spiral sling techniques: alternatives to manage disabling recurrent urinary incontinence in females. J Urol 2010;184:2429-33.

47. Mourtzinos A, Maher MG, Raz S, Rodríguez LV. Spiral sling salvage anti-incontinence surgery for women with refractory stress urinary incontinence: surgical outcome and satisfaction determined by patient-driven questionnaires. Urology 2008;72:1044-8.

48. Kane L, Chung T, Lawrie H, Iskaros J. The pubofascial anchor sling procedure for recurrent genuine urinary stress incontinence. BJU Int 1999;83:1010-4.

49. Milose JC, Sharp KM, He C, Stoffel J, Clemens JQ, Cameron AP. 
Success of autologous pubovaginal sling after failed synthetic mid urethral sling. J Urol 2015;193:916-20.

50. Petrou SP, Davidiuk AJ, Rawal B, Arnold M, Thiel DD. Salvage autologous fascial sling after failed synthetic midurethral sling: greater than 3-year outcomes. Int J Urol 2016;23:178-81.

51. Aberger M, Gomelsky A, Padmanabhan P. Comparison of retropubic synthetic mid-urethral slings to fascia pubovaginal slings following failed sling surgery. Neurourol Urodyn 2016;35:851-4.

52. Shapiro AAC, Rosenblatt PL. Pubovaginal sling with autologous rectus fascia (RFS) versus tension-free vaginal tape (TVT) for a prior synthetic midurethral sling (MUS) failure. J Pelvic Med Surg 2010;16(Suppl 2):S149.

53. Wein AJ. Re: Comparison of retropubic synthetic mid-urethral slings to fascia pubovaginal slings following failed sling surgery. J Urol 2017;198:1214-9.

54. Cardozo L, Hextall A, Bailey J, Boos K. Colposuspension after previous failed incontinence surgery: a prospective observational study. Br J Obstet Gynaecol 1999;106:340-4.

55. Giarenis I, Mastoroudes H, Cardozo L, Robinson D. What do we do when a midurethral tape fails? Rediscovery of open colposuspension as a salvage continence operation. Int Urogynecol J 2012; 23:1117-22.

56. De Cuyper EM, Ismail R, Maher CF. Laparoscopic Burch colposuspension after failed sub-urethral tape procedures: a retrospective audit. Int Urogynecol J Pelvic Floor Dysfunct 2008;19:681-5.

57. Thakar R, Stanton S, Prodigalidad L, den Boon J. Secondary colposuspension: results of a prospective study from a tertiary referral centre. BJOG 2002;109:1115-20.

58. Albo ME, Richter HE, Brubaker L, Norton P, Kraus SR, Zimmern $\mathrm{PE}$, et al. Burch colposuspension versus fascial sling to reduce urinary stress incontinence. N Engl J Med 2007;356:2143-55.

59. Lapitan MC, Cody JD. Open retropubic colposuspension for urinary incontinence in women. Cochrane Database Syst Rev 2016;2: CD002912.

60. Amaye-Obu FA, Drutz HP. Surgical management of recurrent stress urinary incontinence: a 12-year experience. Am J Obstet Gy- necol 1999;181:1296-307.

61. Maher C, Qatawneh A, Baessler K, Cropper M, Schluter P. Laparoscopic colposuspension or tension-free vaginal tape for recurrent stress urinary incontinence and/or urethral sphincter deficiency-a randomised controlled trial. Neurourol Urodyn 2004;23:433-4.

62. Verbrugghe A, De Ridder D, Van der Aa F. A repeat mid-urethral sling as valuable treatment for persistent or recurrent stress urinary incontinence. Int Urogynecol J 2013;24:999-1004.

63. Steele SE, Hill AJ, Unger CA. Concurrent midurethral sling excision or lysis at the time of repeat sling for treatment of recurrent or persistent stress urinary incontinence. Int Urogynecol J 2018;29: 285-90.

64. Jambusaria LH, Heft J, Reynolds WS, Dmochowski R, Biller DH. Incontinence rates after midurethral sling revision for vaginal exposure or pain. Am J Obstet Gynecol 2016;215:764.

65. Rashid TG, De Ridder D, Van der Aa F. The role of bladder neck suspension in the era of mid-urethral sling surgery. World J Urol 2015;33:1235-41.

66. Giusto LL, Zahner PM, Goldman HB. Management of the exposed or perforated midurethral sling. Urol Clin North Am 2019;46:3140.

67. Rovner E, Athanasiou S, Choo MS, Cosson M, Dmochowski R, Gomelsky A, et al. Surgery for urinary incontinence in women. In: Abrams P, Cardozo L, Wagg A, Wein AJ, editors. Incontinence. 6th ed. Bristol (UK): International Continence Society; 2017. p. 1741854.

68. Kelly EC, Winick-Ng J, Welk B. Surgeon experience and complications of transvaginal prolapse mesh. Obstet Gynecol 2016;128:6572.

69. Margules A, Greiman A, Rovner ES. Identifying factors responsible for mesh sling re-explorative surgery: the case for better surgical technique. In: SUFU 2019 Winter Meeting; 2019 Feb 26-Mar 2; Miami (FL). Society of Urodynamics, Female Pelvic Medicine \& Urogenital Reconstruction; 2019;NM105.

70. Cho KJ, Kim JC. Management of urinary incontinence with underactive bladder: a review. Int Neurourol J 2020;24:111-7. 